DOI: $10.5216 /$ racs.v6.66077

\title{
Literaturas indígenas no ensino-aprendizagem de história e cultura indígena
}

\section{Camila Nogueira ${ }^{1}$}

\section{RESUMO}

$\mathrm{O}$ presente artigo reflete o uso de textualidades de matrizes ameríndias no processo de ensino e aprendizagem de história e cultura indígenas, tendo em vista que as representações de povos indígenas do território brasileiro estão presentes em diferentes memórias, nas dos próprios indígenas e na dos não indígenas. Como exemplo é possível sublinhar a de missionários europeus; a literatura (romances, poemas); registros de viajantes do século XIX, cinema nacional, livros didáticos de história, documentos oficiais do Estado brasileiro, entre outros textos que representam um conjunto de interpretações que a partir dos seus enredos e lógicas discursivas influenciam os leitores no processo de "compreensão", por conseguinte, no reconhecimento das diversidades, complexidades e participações históricas das sociedades indígenas. Em razão disso, será utilizado e ressaltado o uso de produções de intelectuais e escritores contemporâneos indígenas como ferramenta para transversalização de olhares e narrativas com distintos vínculos de expressões. Considerando-se, ainda, que as textualidades de matrizes ameríndias podem simbolizar aporte na troca de saberes entre diferentes grupos étnicos sociais, descentralizando, assim, interpretações que excluíram historicamente diferentes sujeitos e grupos sociais.

PALAVRAS-CHAVE: Textualidade indígena. Protagonismo indígena. Representação. Ensino e aprendizagem.

\section{Indigenous literature in the teaching-learning of indigenous history and culture}

\section{ABSTRACT}

This article reflects on the use of textualities of Amerindian matrixes in the process of teaching and learning indigenous history and culture. Bearing in mind that the representations of indigenous peoples in the Brazilian territory are present in different memories, those of the indigenous themselves and that of the non-indigenous. As an example, it is possible to underline that of European missionaries, literature (novels, poems); records of 19th century travelers, national cinema, history textbooks, official documents of the Brazilian State, among other texts that represent a set of interpretations that, from their plots and discursive logics, influence readers in the process of "understanding", for consequently in recognizing the diversity, complexities and historical participation of indigenous societies. For this reason, the use of productions by contemporary indigenous intellectuals and writers will be used and emphasized as a tool for the transversalization of views and narratives with different expression links. Consideration that the textualities of Amerindian matrices can symbolize the

\footnotetext{
${ }^{1}$ Universidade Federal do Maranhão (UFMA), São Luís, Maranhão, Brasil. E-mail: camilaangelr91@gmail.com.
} 
contribution in the exchange of knowledge between different social ethnic groups, thus decentralizing interpretations that historically excluded different subjects and social groups.

KEY-WORDS: Indigenous textuality. Indigenous protagonism. Representation. Teaching and learning.

\section{Introdução}

Nos últimos anos, após a aprovação da Lei n. ${ }^{\circ} 11.645$ de 10 de março de 2008, as produções literárias de autorias indígenas, como ação "estratégica", cresceram significativamente, diante do reconhecimento da necessidade do desenvolvimento de uma educação intercultural num país plural com sistema democrático de direito. Considerando que, historicamente, na memória social, alguns grupos foram privilegiados em detrimento de outros, de acordo com Luís Fernando Herbert Massoni (2017) esse favorecimento "pertencente à elite" introduziu uma narrativa homogênea, subalternizando muitos sujeitos históricos, construindo assim, uma memória oficial com a ocultação de diversos grupos sociais, dentre eles as sociedades indígenas.

Vale lembrar que "o estado brasileiro, desde o início de sua formação, trabalhou com muita intensidade pelo extermínio das populações indígenas" (BRAGA, 2015, p.104). Por consequência, foram violentados fisicamente e simbolicamente com as suas subjetividades negadas e as suas alteridades desconsideradas. Cunha (2012, p.22) afirma: "por má consciência e boas intenções, imperou durante muito tempo a noção de que os índios foram apenas vítimas do sistema mundial, vítimas de uma política e de práticas que lhes eram externas e que os destruíram”. Portanto, passou a ser imprescindível a descentralização de interpretações que não contemplam o protagonismo histórico de outras sociedades e sujeitos que lutam para obterem seus direitos históricos reconhecidos.

Sobre as questões indígenas, houve um aumento significativo das organizações não governamentais de apoio aos índios. No final da década de 1970 (CUNHA, 2012; BICALHO, 2020), os avanços dos "projetos agroindustriais, as pressões sobre as terras indígenas" (SILVA, 2002, p.49) provocaram inúmeras agitações políticas e sociais. No início do século $\mathrm{XX}$, esses povos que oficialmente dados por "extintos", "mas que de fato existiam e resistiam", começaram a se organizar e as suas mobilizações se intensificaram em busca do reconhecimento étnico oficial (SILVA, 2002, p.50), marcando, assim, um momento de conscientização étnica entre os diferentes povos indígenas do Brasil.

Com a elaboração e promulgação da Constituição de 1988, no contexto de redemocratização, as lideranças indígenas tiveram um papel indispensável para legitimar os 
direitos fundamentais dos povos indígenas. Segundo Danilo Braga (2015), mestre em História, indígena do povo Kaingang, se dependesse somente da atuação do estado brasileiro, as sociedades indígenas seriam populações extintas e os sujeitos remanescentes seriam incorporados na sociedade nacional como cidadãos comuns provenientes dos projetos de aculturação, civilização e assimilação.

Sendo assim, como já salientado por John Manuel Monteiro (2001), o reconhecimento das lideranças indígenas representou um avanço para a historiografia brasileira, tendo em vista seus esforços, resistências e lutas para a defesa de seus direitos, para afirmação das suas diferenças culturais, ações que não se limitaram diante da invisibilidade, mas que garantiram a manutenção de suas etnias (SANTOS, 1995). Segundo Manuela Carneiro da Cunha (2012), não existem dúvidas de que os índios foram “atores políticos" atuantes no processo histórico e de suas próprias histórias.

As articulações dos grupos indígenas foram imprescindíveis para uma mudança de conscientização, suas atuações intensas em diferentes regiões do Brasil evidenciaram "o surgimento de um protagonismo indígena atuante e consciente da necessidade da luta social para fins de reconhecimento dos direitos indígenas no Brasil” (BICALHO, 2010, p.24). Por meio desse processo de conscientização e protagonismo, os povos indígenas reafirmam a sua importância e participações na sociedade nacional, assumindo a tarefa de dialogarem as suas experiências históricas com os nãos indígenas (SCARAMUZZI, 2008). À vista disso, uma das ferramentas das quais os indígenas se apropriaram, considerando a sua potencialidade no mundo dos não indígenas, foi a incorporação da escrita como recurso de fortalecimento dentro e fora das comunidades indígenas. "É no processo de escolarização formal que a escrita passa a ser difundida entre as sociedades indígenas" (SILVA; AZEVEDO, 1995, p.162).

Embora essa educação escolar formal a priori seja contrária à educação propriamente indígena, caracterizada pelo ensino específico de cada um dos grupos indígenas, essa apropriação é um recurso estratégico para "salvaguardar a memória” (GUTJAHR, 2008, p.86) e auxiliar na transmissão de saberes as novas gerações indígenas, "como instrumento de conscientização para um maior respeito à cultura indígena, sobre a qual recai o peso do preconceito, violência e voracidade da sociedade moderna" (GUTJAHR, 2008, p.87). Já aos não indígenas serve como recurso para contrapor-se às representações forjadas pelo viés colonialista, idílico, romantizado ou por visões descompromissadas das questões indígenas. 


\title{
1. Escrita indígena como instrumento de resgate
}

Produções de pensadores indígenas vão sendo encaradas como instrumento de resgate e afirmação das diversidades epistêmicas e culturais, atestando os seus posicionamentos diante a história (MONTEIRO, 2001). Como estratégia de resistência, as produções de autoria indígena servem como ferramenta de inclusão das "muitas histórias perdidas [...] que atravessam as fronteiras étnicas e mostram criticamente os limites da etnificação" (OLIVEIRA, 2016, p.71), refletindo, assim, na complexidade e peculiaridade dos diversos grupos étnicos no Brasil. "Fazer literatura indígena é uma forma de compartilhar com os parentes e com os não indígenas a nossa história de resistência, as nossas conquistas, os desafios, as derrotas, as vitórias" (GRAÚNA, 2012, p.275).

Nesse sentido, a escrita de autoria indígena ganhou visibilidade nas últimas décadas como processo de transcrições e reproduções das memórias e experiências históricas dos povos indígenas. "Muitas outras lideranças e outros pensadores indígenas mobilizavam os seus conhecimentos para se posicionar diante da história" (MONTEIRO, 2001, p.74). Luiza Tombini Wittmann (2015) contribui para a discussão ao dizer que:

\begin{abstract}
O exercício constante é colocar em cena o índio enquanto sujeito, guiado pela sua própria leitura do mundo, baseada tanto em experiências históricas, quanto naquelas desencadeadas pelo contato com o branco. Os ameríndios refletiram em seus próprios termos o processo pelo qual passavam, dando significado às novas realidades enfrentadas (WITTMANN, 2015, p.10).
\end{abstract}

Produções que foram incentivadas como subsídios didáticos no processo de educação indígena básica, suprindo o novo modelo de aprendizagem indígena como próprio, com base nas diversidades étnicas de cada grupo. Isso acontece refletindo e recriando individual e coletivamente as suas vivências históricas que vão sendo transmitidas e reproduzidas através de obras escritas em línguas indígenas e portuguesas. São propostas que sistematizam os conhecimentos de tradições orais relacionadas com as experiências dos povos indígenas com a enunciação das diversidades pela interlocução de outro regime de expressão, com a intencionalidade de "resgatar, preservar, e fortalecer conhecimentos produzidos e transmitidos em outros espaços e contextos" (SCARAMUZZI, 2008, p.140).

Numa entrevista exclusiva ao Instituto Ecofuturo, o escritor indígena Daniel Munduruku $^{2}$, professor doutor em educação com diversas premiações, dentre elas o tradicional prêmio literário do Brasil - Prêmio Jabuti, fala da apropriação da escrita como

2 Entrevista com o professor e escritor Daniel Munduruku, ao Instituto Ecofuturo, uma organização sem fins lucrativos que atua desde 1999. Disponível no portal outras mídias, publicada em 04 de março de 2013. 
"elemento aglutinador", um instrumento de visibilidade, servindo como "porta-voz consciente e consistente" das causas indígenas. Nesse sentido, a escrita é um "instrumento estratégico" de fortalecimento e visibilidade, pois como somos cientes, as representações dos povos indígenas partiram de diversas memórias. Em uma breve síntese, as cartas produzidas por religiosos dos séculos XVI ao $\mathrm{XVIII}^{3}$ registraram uma visão genérica e preconceituosa da amplitude e complexidade de cada etnia indígena.

No transcorrer do período colonial, houve a necessidade de firmar alianças, de catequizar e admoestar os que eram subjugados nas lutas pela proteção e fixação de território. Assim, muitos foram convertidos, escravizados, exterminados e, no conjunto, representados como silvícolas, selvagens, bárbaros, sem fé, expressões que solidificaram negativamente a alteridade indígena, fortalecendo imagens preconceituosas sobre os povos indígenas. De acordo com John Manuel Monteiro (2001), essa desqualificação dos povos originários enquanto sujeitos históricos fazem deles eternos prisioneiros de uma imagem isolada e primitiva (MOREIRA, 2019; ALMEIDA, 2010, 2018).

Até muito recentemente, os índios eram sujeitos praticamente ausentes em nossa historiografia. Relegados à condição de vítimas passivas dos processos de conquista e colonização, seu destino inexorável era desaparecer à medida que a sociedade envolvente se expandia (GRACIA, 2010, p.279).

No século XIX, durante a fase de formação e consolidação do Estado Brasileiro, visões europeias influenciaram intelectuais e políticos nas produções de narrativas eurocêntricas que favoreceram a ocultação dos grupos formadores da sociedade brasileira, afro-brasileiros e indígenas (MONTEIRO, 1995, 1994; CUNHA, 1992; DORNELLES; MELO, 2015).

\footnotetext{
O indígena era visto como um sujeito sem história pela historiografia brasileira. E a matriz teórica deste pensamento, que tem suas origens no século XIX acabava condenando o nativo brasileiro ao desaparecimento e seus principais fundadores foram os pioneiros da historiografia no Brasil. Essas ideias encontraram espaços em setores da sociedade, se cristalizaram ao longo das décadas e ainda hoje se fazem presentes (BRAGA, 2015, p.15).
}

Aos povos autóctones um inevitável desaparecimento foi projetando com a integração dos índios como cidadãos comuns pelo processo de civilização gradativo. Fruto de políticas estatais que negligenciaram os povos indígenas, importante lembrar que para esses povos foi reservado um "enquadramento etnográfico e não histórico" (MONTEIRO, 2001, p.5), apesar

3 Os escritos de religiosos, membros da administração colonial, viajantes, ficaram registrados em cartas, relatórios, crônicas, que cito aqui sem a pretensão de esgotar. 
das sinalizações de intelectuais da época ao salientar a participação das sociedades indígenas na construção histórica brasileira.

O séc. XIX foi marcado pelo debate científico a respeito da classificação dos indígenas em termos evolutivos, sendo dado grande destaque à noção de raça. Alguns cientistas postularam a decadência (degenerescência) dos povos da América, havendo dois principais representantes dessa concepção nos estudos e nas discussões ocorridas no Brasil: Von Martius e Varnhagen. Esta era uma questão central para o destino dos índios, pois envolvia duas atitudes políticas contraditórias, enfatizando ora os empreendimentos pedagógicos, ora as práticas repressivas e militares (uma vez que eram concebidos como a caminho da extinção) (OLIVEIRA; FREIRE, 2006, p.94).

Segundo Maria Regina Celestino de Almeida (2017, p.18), "suas ações não eram, absolutamente, consideradas relevantes para a compreensão dos rumos da história". Por isso, suas representações se restringiram ao víeis assimilacionista, ligada às ideias evolucionistas e ao romantismo da época (OLIVEIRA; FREIRE, 2006). Assim, lentamente, esse canário foi sofrendo pequenas modificações com a legitimidade da figura do "índio" ao protagonizá-lo como perfil da representação nacional, abrindo espaço para uma renovação identitária gerida pelo movimento romântico e nacionalista, por meio do enaltecimento que promoveram novas idealizações, tais quais, “o bom selvagem”, "o submisso", "heroico” (DORNELLES e MELO, 2018; ALMEIDA, 2010, 2013; CUNHA 1992).

Contudo, o que fica evidenciado é a modelagem dessas representações pela ambiguidade do engrandecimento versus menosprezo, descrições e definições que se cristalizaram no imaginário dos não indígenas. Nos últimos anos, alguns estudos sintetizaram a complexidade dos processos de incorporação e exclusão das histórias das populações indígenas na historiografia brasileira. Estudos que, de acordo com MONTEIRO (2001), "oferecem o contraponto das dinâmicas locais e regionais para se repensar tanto as abordagens estruturalistas quanto as teses globalizantes das décadas anteriores" (MONTEIRO, 2001, p.226). São interpretações que passam a considerar os indígenas como atores históricos (CUNHA, 2012), refletindo nas "ações conscientes" desses sujeitos históricos. Segundo Monteiro (2001), um dos aspectos mais relevantes nessas construções históricas é o fato da "ação do índio" determinar a "marcha da história", considerando suas múltiplas experiências ao longo da história do Brasil.

Essas novas abordagens, além de problematizarem as invisibilidades das sociedades indígenas, levantam perspectivas capazes de reconhecer a historicidade a partir de suas experiências sociais e cultural. "Essas experiências, vivências e estratégias indígenas vêm sendo esmiuçadas [...] às informações inéditas que emergem, em fragmentos dispersos, dos 
arquivos que guardam e escondem os mistérios do passado" (MONTEIRO, 1999, p. 238). Já no decorrer do século XX, as inquietações foram sendo afloradas e os esforços para aproximar a história de outras ciências no processo de interdisciplinaridade ampliaram espaços para os sujeitos até então "marginalizados" que começaram a ser acolhidos nos estudos e pesquisas das academias. Essas novas abordagens, chamadas de "novas histórias" surgem segundo Le Goff (1998) para "reivindicar a renovação". Sendo assim, os "escritos de todos os tipos, documentos figurados, produtos de escavações arqueológicas, documentos orais, uma estatística, [...] são, para a história nova, documentos de primeira ordem" (LE GOFF, 1998, p. 28-29). Assim são incluídas novas temáticas e o processo de revisão historiográfica é cada vez mais frequente.

Sendo a cultura amplamente estudada por diversas áreas do conhecimento, a mudança em seu conceito, que certamente foi lenta e gerou conflitos, promoveu transformações de ordem social, simbólica e política, representando uma mudança de paradigma no contexto da ciência e da produção de conhecimento (MASSONI, 2017, p.38).

Nesse contexto, a memória da "minoria simbólica" que até então estava à margem nos estudos científicos, passa a ser vestígio de conhecimento histórico, isto nas últimas décadas do século XX e na primazia do século XXI, em razão das novas demandas sociais caracterizadas pela participação mais incisiva das sociedades civis pela construção de um Estado democrático, com a inclusão das culturas "subalternizadas" e as suas manifestações perpassadas por tradições diversas.

Nesse sentido, as modificações na historiografia brasileira podem ser vistas como instrumento capaz de fornecer "fundamentos e diretrizes para a compreensão do desafio teórico e político que os índios apresentam para a sociedade e para o Estado brasileiro" (MONTEIRO, 1995, p.227), caminhando gradativamente para o reconhecimento das diversidades e da inclusão de visões produzidas por outros sujeitos. Embora ainda de forma tímida, os povos indígenas passam a serem revistos como protagonistas nos contextos múltiplos na história do país, quando a historiografia passou a considerar as sociedades indígenas como capazes de "traçar a sua própria história" (MONTEIRO, 1995; CUNHA, 1992).

O escritor indígena Daniel Munduruku descreveu que a atuação dos movimentos sociais oportunizou a "tomada de consciência e aquisição de instrumentos teóricos" obrigando a história escrita a "mudar de rumo" e aceitar compulsoriamente "novas visões" e participações na história brasileira. Em suas palavras: 
Isso é muito importante para compreendermos como a tomada de consciência está intrinsecamente ligada ao processo de apoderamento do mecanismo ou instrumental teórico ocidental. Esta capacidade de alargar os horizontes mentais para enxergar de forma mais clara o entorno, o nacional exigiu nova postura e redirecionamento do que era, até então, dado como verdade (MUNDURUKU, 2012, p.211).

O escritor ressaltou também que é provável que a grande contribuição dos movimentos sociais, ressaltando aqui o movimento indígena, seja a revelação e a denúncia para a sociedade geral da existência da "diversidade cultural e linguística" da nação, onde os grupos que eram vistos como "genéricos" são revistos como um "fato real" (MUNDURUKU, 2012, p.222). Porém, o processo de conhecimento e reconhecimento por parte dos não indígenas tem sido em passos lentos. Segundo a historiadora Luisa Tombini Wittmann (2016), o estranhamento do protagonismo das sociedades indígenas pelos não indígenas "não é de se espantar", pois infelizmente "este não é um assunto corrente", o que faz com que essa temática permaneça no campo do desconhecimento, mantendo, assim, visões equivocadas. Por isso, ao refletir sobre a temática indígena, a autora faz um convite para "estimular um debate essencial sobre a nossa história, suscitando o respeito às referências culturais indígenas e a valorização da diversidade da sociedade brasileira" (WITTMANN, 2016, p.288).

\footnotetext{
Quando se conta uma história, seja ela das missões jesuíticas no período colonial ou da atual luta pela demarcação de terras, o grande tema é o contato entre populações não indígenas e indígenas. Encontros e desencontros entre sujeitos que geralmente pensam e agem de maneira distinta. Todavia, esta relação entre sujeitos diferentes não deve ser pensada como um choque entre blocos imutáveis, onde os ditos vencidos aparecem como resistentes culturais, sobreviventes descaracterizados, à espera do desaparecimento ou já vítimas do extermínio. A história do contato foi e é muito mais interessante. Podemos recontá-la reconstruindo conflitos, diálogos, tensões e negociações. Uma história na qual os índios são protagonistas percorrem caminhos que eles mesmos construíram (WITTMANN, 2016, p.2).
}

Contudo, é indispensável que se faça continuamente o "destrinchamento das representações" (WITTMANN, 2015), considerando as múltiplas experiências com sociedades de tradições distintas para o rompimento dos discursos colonialistas, possibilitam novos panoramas da história do Brasil a partir das resistências culturais e lutas sociopolíticas.

Sendo assim, é importante refletir sobre as distintas concepções formadoras da sociedade brasileira, considerando que elas se orientam por outras imagens, por outros registros e outros olhares, e linguagens. Pois, é fundamental a projeção de novos horizontes, a este respeito Jonh Manuel Monteiro (1995) aponta a adoção de outros gêneros de discursos históricos para rever os preconceitos e conceitos sobre as sociedades indígenas, qualificandoas numa dinâmica de "ação consciente" como autores históricos que foram e são. É imprescindível as revisões das abordagens captadas pelos olhares colonialistas que reservaram 
a esses autores uma perspectiva homogênea frente as suas divergentes formas, suas reconfigurações, o "caráter híbrido", desenvolvido com as interações sociais pós-contato. Portanto, mais que resgatar é preciso "oferecer diretrizes para a compreensão do desafio teórico e político que os índios apresentam para a sociedade e para o Estado Brasileiro" (MONTEIRO, 1995, p.227).

Um dos mais importantes intelectuais indígenas da contemporaneidade, Ailton Alves Lacerda Krenak, falando sobre história indígena no Brasil, salienta a complexidade e a riqueza das sociedades indígenas. Em suas palavras, “(...) ela tem uma complexidade e riqueza, seria como tentar entender os grãos e areia de uma imensa praia [...] a complexidade de uma constelação de estrelas falando de cada uma” (KRENAK, 2012, p.115). Nesse contexto, Ailton Krenak diz que "não tem transversalidade que resolva a particularidade da história indígena no Brasil", pois quem estava anteriormente extinto vai ressurgindo como indivíduo, como coletivo no autorreconhecimento e autorrepresentação.

Assim, a escrita indígena é uma ferramenta no desenvolvimento de novos olhares sobre os povos autóctones, representando uma retomada do "poder de autoria" e de representação que estava sobre o domínio dos não indígenas. Ainda de acordo com Ailton Krenak, as referências históricas da sociedade brasileira aos povos indígenas são reflexos nos quais os "índios" não tiveram nenhum protagonismo, ou quando eram vistos, estavam em eventos como "vultos" assim "lá no fundo do quintal", "nas clareiras mais remotas". Portanto, a escrita indígena tem relação direta com a luta social das sociedades autoctonias de saírem desses espaços escondidos para estarem considerando as suas próprias experiências e vivências históricas como agentes históricos ativos.

É nessa perspectiva que a nova história indígena está em plena confluência. No campo acadêmico, cresceram os estudos e pesquisas interdisciplinares com o esforço contínuo de tentar evitar as meras repetições dos "discursos unilaterais" (WITTMANN, 2015). Intelectuais que se mantém com seus olhares atentos, caminhando para além dos "filtros ocidentais", revisando e acessando os "códigos da cultura indígena no escrito do outro" (WITTMANN, 2016).

Historicamente, as parcerias entre grupos indígenas e estudiosos da questão indígena ligados à academia foram fundamentais. Primeiramente para alguns grupos indígenas, já que elas auxiliaram esses grupos a se organizarem politicamente e aprimorarem progressivamente o controle e a qualidade das relações de intercambio com a sociedade nacional (SCARAMUZZI, 2008, p.12). 
Segundo o historiador, doutor em antropologia social, Igor Alexandre Badolato Scaramuzzi (2008), este desvencilhar das visões de matrizes positivistas por parte dos intelectuais e a participação ativa dos grupos indígenas colaborou para uma nova forma de compreender e abordar a história dos índios. A partir das emergências do reposicionamento do lugar do índio na construção histórica nacional e a urgência da afirmação da presença indígena pela autorrepresentação, a apropriação da escrita tornou-se uma estratégia no processo de reivindicação política. De acordo com o antropólogo João Pacheco de Oliveira (2016), as vozes indígenas como mecanismo de oposição ao colonialismo começam a ser reconhecidas e ouvidas nas últimas décadas, por isso estamos lidando com um desafio grande de reposicionar um lugar que foi tirado dessas sociedades. Oliveira afirma:

\footnotetext{
Recolocar os indígenas como agentes efetivos na construção do Brasil não é uma tarefa com repercussões restritas e pontuais. À semelhança de mexer em um castelo de cartas, somos involuntariamente conduzidos a rever as interpretações mais frequentes e consagradas que eminentes historiadores, sociólogos, geógrafos, economistas e antropólogos formularam sobre o país (OLIVEIRA, 2016, p.8).
}

Neste ponto, considero importante dizer que as parcerias entre as ciências humanas e as sociedades indígenas estimularam uma nova consciência histórica e que, embora a visibilidade e os olhares sobre os escritores indígenas sejam recentes, as sociedades indígenas não estavam "alheias a algumas formas de registro". Neumann reitera:

\footnotetext{
Diversos materiais como argila, palha, madeira serviam como suportes para representações gráficas e atuavam como recursos mnemotécnicos por essas sociedades para armazenar conhecimentos através da codificação simbólica de elementos do mundo natural, social e sobrenatural. Portanto, essas sociedades indígenas, apesar do seu agrafismo, ou iletrismo, dispunham de um estoque de recursos que contribuíam para a reprodução de informações; não estavam totalmente alheias a algumas formas de registro (NEUMANN, 2005, p.34).
}

Os estudos e pesquisas da área da arqueologia, antropologia cultural, etno história, histórico-antropológico (CUNHA, 2012; MONTEIRO, 1995; FAUSTO, 2001; OLIVEIRA, 2016) começaram a apresentar novas interpretações a partir de "metodologias híbridas", ou seja, estudos cruzados pela interdisciplinaridade (SILVA, 2019, p.32). Pesquisas evidenciaram que muitos grupos étnicos indígenas já possuíam uma forma de escrita no sistema de "ideogramas e pictogramas", antes da chegada dos europeus, sistemas que expressavam suas representações em um "sentido narrativo" como técnica de registro e de identificação. que foram utilizados, além da memória oral. Por exemplo [...] desenhos e figuras 
que representam simbolicamente um conjunto de mitos e histórias com informações sobre as origens das tribos (FREIRE, 2008, p.17).

Portanto, a lógica de "narrativa gráfica" para muitos grupos étnicos indígenas já estavam sendo desenvolvidas, nos primórdios, com o objetivo de preservar, registrar, narrar e transmitir as suas tradições, acontecimentos históricos, conquistas e as suas subjetividades, criando, assim, uma rede de vestígios distribuídos pela América.

Os índios tinham o costume de perpetuar, por escrito, a lembrança dos principais acontecimentos de sua história através de uma forma de escrita que era em parte pictográfica, pois combinava desenhos figurativos para obter deles um sentido narrativo, e era em parte ideográfico, já que expressava diretamente os sons para a representação de significados ou ideias, com a fonetização das figuras (FREIRE, 2008, p.9).

Este rico painel de produções de tradições indígenas reforçam a complexidade dessas sociedades e a importância como autores políticos e sociais de suas próprias histórias. As vozes indígenas, suas resistências e lutas, o processo de representação e autorreconhecimento estimularam também a autorrepresentação que, de acordo com Oliveira (2016), estabeleceu uma "interlocução duradoura" dando espaço para o sujeito histórico tanto subjetivamente como coletivamente, colaborando para que sejam criados panoramas de vozes que "engendra muitas expectativas", mostrando detalhes que ficaram despercebidos ou "não ditos". Este é um processo também de recuperação da memória.

\footnotetext{
Os estudos dedicados a analisar a transliteração da oralidade para o registro escrito têm privilegiado questões relativas à capacidade de apropriação do texto (escrito) e dos diferentes níveis de domínios das práticas letradas por parte de sociedades em que esse recurso inexistia. Trabalhos estimulados por essa orientação teórica têm voltado sua atenção para a análise histórica do escrito e para as implicações decorrentes da mudança de um regime de registro (oral) para o outro (escrito), mas sem deixar de considerar as formas de circulação do texto em situações sociais mais oralizadas (NEUMANN, 2005, p. 34).
}

As escritas indígenas, as textualidades de matrizes ameríndias, se apresentam como recursos estratégicos de resgate histórico por parte dos indígenas aos não indígenas, possibilitando novas interpretações. Sobre isso, Aliria Wiuira Benicios de Carvalho destaca:

... a prática escritural serve de preservação das histórias orais. As narrativas orais não são apenas um ritual diário de relatos com personagens humanos, animais, sobrenaturais, florestas, rios. São riquezas semeadas na mente de quem ouve e um dia recorre à memória para transmitir o que foi lhe repassado (CARVALHO, 2016, p.104). 
Embora haja alguns debates sobre as transcrições dessas tradições orais para regime de registro escrito, da "exposição do saber", é preciso que haja a validação dos "guardiões dessa sabedoria”. A respeito disso, o indígena Zaqueu Key Claudino (2013), pertencente ao povo Kaingang, defende que esse deve ser um papel desenvolvido pelos anciões, pajés, ou por quem seja habilitado para acessar intrinsecamente esses conhecimentos. Importante considerar, também, que "tradições orais consistem em modos expressivos e discursivos adequados a modalidades de interação segundo contextos precisos" (GUTJAHR, 2008, p. 200). Os intelectuais indígenas têm problematizado esse processo de transferência de registro escrito com efeito de sistematizar o seu conhecimento (SCARAMUZZI, 2008), sendo preciso fazer um filtro, tendo em vista o uso irresponsável ou despreocupado das demandas das comunidades de onde esses saberes são colhidos.

\begin{abstract}
A exposição dos saber coletivo deve realmente ser filtrada, lembrando que os muros ou o muro não é construído sem nenhum motivo específico: são erguidos com propósito de guarda a memória dos antepassados. Aquele conhecimento especial, que muitas vezes é somente o pesquisador indígena ou o jamré (cunhado, genro) que pode acessar e usufruir dele, na verdade não é por que a pessoa não tem a capacidade de absorver, mas é porque há conhecimentos que só poderão ser acessados na singularidade entre os jamré, ou vice versa (CLAUDINO, 2013, p.113).
\end{abstract}

O trecho acima tenciona a preocupação de muitos representantes e líderes indígenas que desejam que suas narrativas sejam transcritas de forma mais original daquilo que foi transmitido por seus ancestrais, para não haver o risco de distorções das realidades compreendidas por eles a partir de seus simbolismos e cosmovisões (GUTJAHR, 2008, p.87).

Gutjahr afirma:

\begin{abstract}
Já testemunhamos os riscos de tais propostas de "valorização", em especial no que diz respeito à tradução de valores indígenas (como sua relação com seus ancestrais e importância de seus velhos) a partir de conceitos termos ou imagens que correspondem a nossas formas de avaliação (GUTJAHR, 2008, p.204).
\end{abstract}

Apesar dos riscos, são diagnosticados pontos positivos nas transcrições. Zaqueu Kaingang (2013) sobre essa questão reflete que "sempre teremos ao nosso lado, pessoas simpatizantes ou pesquisadores indígenas que precisam manter o saber em evidência na escrita e na oralidade" (CLAUDINO, 2013, p.114). É esse saber em evidência que colabora com a criação de recursos paradidáticos e didáticos na transmissão de saberes. O indígena Igor Badolato (2008) afirma que os materiais didáticos de conhecimento indígena podem ser vistos como "retórica discursiva" para comunicar, traduzir e enfatizar as diferentes culturas, por isso deve ser valorizado e incentivado. 
A indígena Alíria Wiuira (2016) também reforça que as transcrições servem de suporte, no processo educativo, mesmo que na escrita alguns sistemas de expressões não sejam percebidos. Os textos ligados a cosmovisão indígena se transformam em instrumentos para inserção de conhecimento para os nãos índios e, também, para que os indígenas de outras etnias possam ter acesso aos saberes de outros grupos, "ainda que o narrador não esteja presente. Por meio da escrita, o sujeito confere ao texto as experiências coletivas" (CARVALHO, 2016, p. 104). Deve-se considerar, ainda, que é preciso apreciar as ações dos sujeitos em seus múltiplos aspectos sociais, observando mais atentamente os vestígios para notar as dinâmicas de suas participações na construção histórica, substituindo, assim, erros aprendidos.

É preciso substituir a noção simplificadora de erro pela de apreensão da multiplicidade de usos sociais, pois é por meio dessas representações que os agentes sociais e as épocas irão registrar (ou não) a presença de indígenas, bem como se relacionar com eles. Por isso mesmo, sua identificação e análise são imprescindíveis para a Antropologia e para uma abordagem historiográfica dos múltiplos usos da história, com o estabelecimento de uma postura mais vigilante quanto aos saberes constituídos (OLIVEIRA, 2016, p.78).

Nisto pretende-se analisar e "estabelecer como aí funcionou, efetivamente, um regime de memória, associando ações, narrativas e personagens, e lhes integrando em formas de construção de significados" (OLIVEIRA, 2016, p. 26). Em razão dos múltiplos efeitos do esquecimento, dentre eles, a marginalização de diversos grupos sociais, faz-se necessária uma "reconstrução simbólica" (OLIVEIRA, 2016, p. 78). Portanto, as textualidades de matrizes ameríndias fornecem subsídios de resgate histórico para a sociedade de modo geral, considerando a necessidade de uma reconstrução simbólica na memória social nacional e até mesmo indígena. Pois, em conformidade com Zaqueu Kaingang (2013), os anciões, quando morrem, levam consigo todo o conhecimento armazenado em suas memórias, por isso a preocupação dos intelectuais indígenas em captarem aquilo que existe de essencial nesses saberes, estando engajados com o devir, reescrevendo a história, as suas próprias histórias.

\section{Textualidade de matriz ameríndia}

A indígena Alíria Wiuira (2016) faz um levantamento das textualidades Guajajara catalogando alguns registros sobre as narrativas orais presentes nesta etnia. A autora mostra que os textos de matrizes ameríndias surgem das subjetividades e particularidades de cada povo frente às suas tradições e experiências históricas. Dessa maneira, os textos carregam 
intrinsicamente o campo de vivência dessas comunidades indígenas, "as sociedades indígenas apresentam um repertório de narrativas que, conforme as situações de interação são pronunciadas de acordo com a finalidade" (CARVALHO, 2016, p.74). Ou seja, as produções de autoria indígena surgem como um material que aponta as visões dos ameríndios, contendo apreciação das suas consciências históricas como sujeitos políticos e ativos e não como simples coadjuvantes deste processo.

As produções, embora carreguem consigo olhares peculiares, evidenciam uma relação com a coletividade, "as textualidades indígenas surgem por intermédio de representantes de etnias que a utilizam como instrumento de divulgação dos seus costumes" (SANTOS, 2017, p.77). Não são somente produções baseadas em tradições orais, mas sim, marcadas pelas autoetnografias que devem ser entendidas por sua heterogeneidade. Para Emilio Del Valle (2015), tratam-se também de uma ampla reflexão de poderes, direitos, recriações estéticas, política, na qual os indígenas reivindicam seus espaços, em um ato de representação alternativo de novos horizontes contra a violência simbólica exercida sistematicamente através das distintas ações sociais e políticas a que foram e ainda são submetidos.

Em função disso, essas produções estimulam um ponto de partida para aquisição de outros conhecimentos sobre os povos indígenas, numa tarefa de reinterpretação discursiva e conceitual, onde os textos de autoria indígena sinalizam vozes indígenas ecoando em um ambiente multicultural. No trabalho das autoras Maria Inês de Almeida e Sônia Queiroz (2014) com o tema "Na captura da voz; as edições da narrativa oral no Brasil" é ressaltado que assim como os viajantes europeus do século XVI e XVII representaram o "novo mundo" e as sociedades que encontraram no Brasil, agora os nativos revertem esse processo, apresentando o Brasil pela ótica dos escritores indígenas.

Trata-se de uma deliberação política. Os escritores indígenas o fazem de um território imaginário, em que as coisas se renomeiam, no exercício da ocupação do solo simbólico. A escritura é coletiva porque é expressão do que é comum, ou de um consenso em torno do "quem somos". É política porque reordena a coletividade, valendo-se das palavras pronunciadas pelos seus representantes. Cada livro editado nesse processo de criação literária serve para indicar que é a partir da terra que os livros são escritos. Assim como nossa tradição literária europeia se baseia na textualidade (ou representação) - um livro nasce de outro livro, e assim por diante as várias literaturas indígenas servem-se da territorialidade: cada trecho de livro copiado, cada voz transcrita, cada tradução interlíngua, cada parte do mosaico, que são os livros aqui referidos, é um pedação de terra concretamente desapropriado e reapropriado ao mesmo tempo (ALMEIDA; QUEIROZ, 2004, p. 197-198).

As autoras apontam que a oralidade era a primazia há menos de 300 anos no Brasil e que o letramento, os impressos vão sendo inseridos por intelectuais que tiveram suas formações marcadas por influências externas. Mas nas últimas décadas, os trabalhos e 
pesquisas estão se direcionando para questões internas oriundas de "sujeitos capazes de traçar a sua própria história” (MONTEIRO, 2001, p.75). É nesse sentido que as autoras descrevem que "os escritores indígenas estão descobrindo o Brasil” (ALMEIDA; QUEIROZ, 2004, p.195).

Cerca de quarenta povos indígenas do Brasil já tiveram suas textuais publicadas e divulgadas em livros e cartilhas que, "quase sempre, se dirigem disfarçadamente aos brancos para redesenhar o seu terra à vista" (ALMEIDA; QUEIROZ, 2004, p. 195), por exemplo, obras de escritores contemporâneos compromissados com as demandas sociais de suas comunidades e dos seus parentes ${ }^{4}$, dentre eles as indígenas Graça Gráuna (1999; 2001; 2007; 2010). Eliane Potiguara que trabalha com projetos de "propriedade intelectual" indígena, (1989; 1994; 2004; 2012; 2015; 2018); o doutor em educação Daniel Murunduku, com mais de 40 publicações diversas e infanto-juvenis, são alguns dos indígenas engajados com o "fazer literatura indígena" (GRAUNA, 2012, p.275), como instrumento de compartilhamento de suas histórias e resistências.

Dito isto, as textualidades de matriz ameríndia simbolizam um recurso de manutenção das tradições e reconhecimento de distintos vínculos de expressões, são aporte na troca de conhecimento dos saberes indígenas, um recurso de comunicação com diferentes grupos étnicos sociais, colocando os indígenas na centralidade de inserção de outros saberes. “A inclusão dos saberes indígenas significa mais do que apresentar a diversidade cultural. Significa dialogar a partir da multiplicidade de seus conhecimentos, suas sabedorias e suas cosmovisões e estabelecer a interlocução com os conhecimentos ocidentais" (BRIGHENTI, 2016, p.249).

Sendo assim a prática da escrita pelos indígenas têm possibilitado não só visibilidade, mas uma "conjugação de vários elementos", numa perspectiva, "forma-sujeito, uma entidade representativa, muitas vezes plural.” Em concordância com Emilio Del Valle (2015), os textos são retratos de um projeto cultural de afirmação que envolve atores coletivos na luta por seu reconhecimento. Pois, os povos da América latina estão longe de terem suas atuações neutras e apáticas, são povos ativos e conscientes, por isso, as suas textualidades tornam-se um ato de representação cultural e social em combate as contradições da "imagem do índio" na memória histórica que devem ser vistas, revistas, analisadas e discutidas. É um constante exercício para romper com a colonialidade, tendo como foco o desenvolvimento de novos olhares a partir de

\footnotetext{
4 Uso o termo "parentes" de acordo com a explicação do indígena Gersem Baniwa (2006) que se refere à expressão parente não como semelhantes, mas como sinônimo de vínculo étnico-identitário de grupos indígenas com interesses comuns na luta pela autonomia sociocultural frente à sociedade global.
} 
percepções produzidas pelos indígenas em um panorama complexo, em contrapartida, dos padrões ocidentais. "O objetivo é, portanto, um lugar de reconstrução da memória indígena no Brasil, embora também se construa sobre os escombros da sua história, sobre o esquecimento do seu passado" (ALMEIDA; QUEIROZ, 2004, p.200).

Segundo Almir Diniz de Carvalho Júnior (2016), o que sabemos sobre processos de representações produzidos pelos indígenas ainda é insignificante e ainda estamos frente a problemas de contexto eurocêntrico. Para o autor, "as sociedades indígenas sofreram um processo de esvaziamento de verdade e estariam atreladas a uma visão ingênua e pouco científica" (2016, p.77). Dito isto, é importante ressaltar que as produções contemporâneas também passam por esse processo, mas é preciso considerar, conforme Pedro Cesariano (2015, p.77), que as matrizes ameríndias se orientam distintamente com linguagem própria e, em razão disso, o uso delas representaria novos ciclos de referências, pois grande parte das representações do "mundo indígena" que estão presentes na memória histórica são feitas por não indígenas, ainda que solidarizados com suas causas.

A escrita indígena é também uma reação em um gesto antropofágico da ressignificação (ALMEIDA; QUEIROZ, 2004) frente aos preconceitos e a invisibilidade pela prática intertextual.

\footnotetext{
Os textos podem ser tomados como a própria historicização da questão indígena, é reinvestigando seu passado que os povos escapam da ambiguidade traumática dos recalques e rejeições inconscientes. A memória histórica, nos locais onde a história foi e continua a ser um combate sem testemunhas, armas a coletividade de forcas e decisões novas e lhe permite ultrapassar os dejetos inconscientes da estruturação imposta, autorizando a refletir concretamente sobre a necessidade ou não de determinadas estruturas, como a necessidade da escrita, por exemplo. Parto do pressuposto de que a escrita é estruturante do ser no mundo e de que a memória de que estamos tratando é coletiva e operatória, isto é política (ALMEIDA; QUEIROZ, 2004, p.203).
}

Ao falar sobre "o futuro da questão indígena" no início da década de 1990, a antropóloga Manuela Carneiro enfatizava a importância dos conhecimentos acumulados pelas gerações de povos indígenas, conhecimentos que colaboram para o desenvolvimento do país, considerando o estabelecimento de um "planejamento estratégico" que, além de beneficiar a nação, ressaltava a importância do papel das populações tradicionais. Com base nesse contexto considero o uso de textualidades indígenas um instrumento imprescindível no processo de diálogo da temática indígena na sala de aula.

Uma das premissas desta pesquisa é analisar o nível de sensibilidade dos professores em transpor para a classe assuntos que ressignifiquem os povos originários com base em novos panoramas historiográficos, evitando concepções eurocêntricas. Em vista disto, é 
importante identificarmos primeiramente quais representações estão presentes em suas memórias e quais têm sido seus respectivos recursos e subsídios para o ensino de história indígena, considerando como fundamental que esses profissionais tenham um envolvimento genuíno, observando que o "não lugar" dos povos indígenas não foi e nem é um ato involuntário do sistema, pelo contrário, foi e é um "ato intencional" de omissão, desvalorização que precisa ser superado.

A historiadora Luísa Wittmann (2016) ao escrever sobre "formação de professores na temática indígena" reforça a importância do "enfrentamento da discriminação" e a necessidade da aquisição por parte dos professores de novos conhecimentos que ajudem na superação dos estereótipos destinados às sociedades indígenas, explorando assim outras possibilidades dentre elas a "rede de interação" como estratégia pedagógica.

\footnotetext{
Nos últimos anos, os próprios índios passaram a produzir e a veicular imagens em vídeo, divulgadas pelas aldeias e pelos fóruns urbanos. As organizações indígenas, através de publicações, vídeos, CDs e seus sites têm procurado manter informada a opinião pública não só das demandas e propostas políticas indígenas, mas também sobre a sua cultura (PACHECO; FREIRE, 2006, p. 160).
}

Tanto as produções de autorias indígenas, quanto os materiais desenvolvidos pelos próprios indígenas são extremamente válidos, desde que compromissados com as demandas sociais das suas comunidades, direcionados para preservação e revitalização de suas culturas, dos saberes, das memórias e vivências dos seus respectivos grupos (SCARAMUZZI, 2008). Além disso, é necessário estarem interligados em um sentimento de compartilhamento afetivo, respaldados nas memórias coletivas de suas comunidades, mantendo a responsabilidade de legitimarem as suas narrações no contexto de lutas políticas de afirmação indígena (MURA, 2016).

Considerando esses filtros, as produções de autorias indígenas são um suporte paradidático sobre a temática para o ensino de história e culturas indígenas, em sala de aula, também para os não indígenas, conforme Daniel Munduruku (2017), "no caso da cultura indígena, as histórias mostram a força da natureza, a diversidade cultural, o respeito aos antepassados, a origem das coisas, os desafios de ser criança e tomar decisões". No meio do esquecimento, a escrita de autoria indígena reincorpora o lugar de falar desses sujeitos históricos, carregando consigo uma memória ancestral que foi negada por tantas vezes na memória social dos não indígenas. 
marca do mundo indígena é a diversidade de povos, culturas, civilizações, religiões, economias, enfim, uma multiplicidade de formas de vida coletiva e individual. (BANIWA, 2006, p.31).

As escritas indígenas, nesse sentido, são capazes de suprir algumas carências promovendo um panorama mais diversificado de quem são os indígenas no Brasil, pois, como somos cientes, a sociedade brasileira possui certa dificuldade de reconhecer essas sociedades, e "para a compreensão das culturas indígenas, é importante notar não apenas o que os olhos veem, mas também tudo aquilo que escapa à primeira vista e que pode estar vivo e pulsante em determinada comunidade" (SILVA; COSTA, 2018, p.65).

Daí a importância de se levar estas textualidades para a sala de aula, para representar, incluir, concepções múltiplas que agregam valores simbólicos das tradições orais de acordo com as comunidades das quais estes textos estão inseridos, pois, são escritos desenvolvidos pela óptica indígena, contribuindo para a afirmação de que somos uma sociedade historicamente pluriétnica e multicultural. Escritos estes que atuam como um instrumento de aprendizado sobre suas culturas materiais e imateriais que constituem "um patrimônio inestimável ao Brasil, e conhece-las, preservá-las e respeitá-las faz parte da formação cidadã de todo brasileiro" (SILVA; COSTA, 2018, p.39).

De acordo com Giovani José da Silva e Ana Maria (2018), o ensino e aprendizagem da temática indígena, nas instituições escolares, sofrem com a urgência da aplicabilidade de discussões mais crítica-reflexiva, pois, o seu desenvolvimento ainda produz estereótipos e, ao invés de minimizarem, continuam sendo promotoras de ideias preconceituosas e discriminatórias dessas minorias. Nessa perspectiva, não são mais aceitas as teorias de aculturação (SILVA; COSTA, 2018) por disseminarem o senso comum e desconsiderarem a subjetividade de aquisição desses elementos (matérias e imateriais), tendo em vista que, "as leis, por si só não modificam a realidade e tampouco servem como único parâmetro para se perceber a sociedade brasileira" (SILVA; COSTA, 2018, p.101). Silva e Costa acrescentam, ainda:

\begin{abstract}
Assegurar o cumprimento dos preceitos constitucionais consiste em um desafio que está posto a todos nós. Os índios, suas organizações, entidades de apoio, universidades, ministério publico, sociedade brasileira e seus diversos componentes devem ser os responsáveis pela promoção do reconhecimento da diversidade cultural indígena (SILVA; COSTA, 2018, p.112).
\end{abstract}

Desse modo, a literatura indígena, para o ensino de história e cultura das sociedades autóctones, é um exercício para que fiquemos atentos às complexidades e as múltiplas visões e cosmovisões de grupos étnicos distintos. Assim, caminhamos em direção a novos 
horizontes, sendo um recurso de inspiração para novas reflexões que elucidem o protagonismo dos povos indígenas livres das perspectivas colonialistas.

\section{Considerações finais}

Como podemos perceber, os autores indígenas contribuem significativamente com as suas representações, imagens, memória, reconhecimento, identidade. As textualidades representam de certa forma a retomada de controle por parte das sociedades indígenas sobre as narrativas que ajudam na redefinição dos "índios" frente à memória social hegemônica, em outras palavras, "ao assumir a narrativa da História, o índio passa do falar do ventríloquo para uma etapa em que a "pele silenciosa" se transforma em "pele sonora", cuja voz ecoa pelo mundo" (THIÉL, 2012, p.94). A este respeito Manuela Carneiro da Cunha (1992) salienta que as relações estabelecidas na sociedade brasileira seguem em uma trajetória de compartilhamento, pois, as sociedades indígenas pensavam e refletiam no que lhe aconteciam em seus próprios termos.

Portanto, a literatura indígena serve para aproximar as sociedades indígenas dos não indígenas, tendo em vista as transformações do processo histórico como objeto de questionamento e reflexão, a partir da inclusão de repertórios teóricos de autoria indígena que permitam o avanço na aquisição de novos saberes. Bittencourt (2009) destaca a importância de se combater um ensino de História que não colabore com o domínio conceitual diversificado, que não mobilize as diferentes formas de pensar, caso contrário, não será estabelecido um pensamento histórico crítico reflexivo.

As literaturas indígenas no ensino-aprendizagem de história e cultura indígena ampliam a "rede conceitual" ressignificando progressivamente conceitos históricos, colaborando para novos conhecimentos. Para tanto, torna-se fundamental levar em conta que as diversidades das produções de autores indígenas representam um conjunto de repertório com perspectivas múltiplas, a partir das quais funcionarão como ferramentas de transversalização no ensino de história e cultura dos povos originários. Segundo Geam Karlo e Cynara Desiee (2015), quanto maior for o contato dos alunos com modelos diversos de textos disponíveis na sociedade e na escola, maior serão as suas possibilidades de compreensão das expressividades histórico-culturais existentes. 


\section{Referências}

ALMEIDA, M. I. de; QUEIROZ, S. Na captura da voz: as edições da literatura oral no Brasil. Belo Horizonte: Autêntica, 2004.

ALMEIDA, M. R. C. de. Os índios no tempo da corte: reflexões sobre política indigenista e cultura política indígena no Rio de Janeiro oitocentista. Revista USP, (79), 2008, p. 94-105. https://doi.org/10.11606/issn.2316-9036.v0i79p94-105. Disponível em: < https://www.revistas.usp.br/revusp/article/view/13697>. Acesso em: 15 jan. 2021.

Os índios na história do Brasil. Rio de Janeiro: Editora FGV, 2010.

Os índios na História do Brasil no século XIX: da invisibilidade ao protagonismo. Revista História Hoje, São Paulo, v. 1, n. 2, p. 21-39, 2012.

A atuação dos indígenas na História do Brasil: revisões historiográficas. Rev. Bras. Hist. [online], 2017, v.37, n.75, p.17-38. Epub Aug 17, 2017. ISSN 18069347. https://doi.org/10.1590/1806-93472017v37n75-02. Disponível em:< https://www.scielo.br/pdf/rbh/v37n75/1806-9347-rbh-2017v37n75-02.pdf $>$. Acesso em: 20 dez. 2020.

AZEVEDO, M.M; SILVA, M.F. Pensando as escolas dos povos indígenas no Brasil: o movimento dos professores • Indígenas do Amazonas, Roraima e Acre*. In A. L. Silva \& L. D. B. Grupioni (Orgs.), A temática indígena na escola: novos subsídios para professores de $1^{\circ}$ e $2^{\circ}$ graus. Brasília, DF: MEC/MARI/UNESCO, 1995. p. 149-166.

BANIWA, G.S.L. O Índio Brasileiro: o que você precisa saber sobre os povos indígenas no Brasil de hoje. Brasília: Ministério da Educação, Secretaria de Educação Continuada, Alfabetização e Diversidade; LACED/Museu Nacional, 2006. Disponível em: http://www.educadores.diaadia.pr.gov.br/arquivos/File/pdf/indio_brasileiro.pdf. Acesso em: 21 jun. 2020.

BICALHO, P. S. S. Protagonismo indígena no Brasil: movimento, cidadania e direitos (1970-2009). 2010. Tese (Doutorado em História) - Universidade de Brasília, Instituto de Ciências Humanas, Departamento de História, Brasília, 2010.

BITTENCOURT, C. M. F. Ensino de História: fundamentos e métodos. 3. ed. São Paulo: Cortez, 2009. (Coleção Docência em Formação - Série ensino fundamental).

BOENO, R. M; GISI, M. L; FILIPAK, S. T. O contexto brasileiro e a formulação da educação básica. In: Congresso Nacional de Educação, XVII, 2015, Curitiba. Anais. Curitiba: Pucpr, 2015. p. 20942 - 20958.

BRAGA, D. A história dos Kaingang na luta pela terra no rio grande do sul: Do silêncio, à reação, a reconquista e a volta para casa (1940-2002). 2015. Dissertação. (Mestrado em História), Programa de Pós-Graduação em História. Instituto de Filosofia e Ciências Humanas. Universidade Federal do Rio Grande do Sul. Terra Indígena Serrinha, 2015.

BRIGHENTI, C. A. (2016). Colonialidade do poder e a violência contra os povos indígenas. PerCursos, 16(32), p. 103-120. https://doi.org/10.5965/1984724616322015103 
Disponível

em: <https://www.periodicos.udesc.br/index.php/percursos/article/view/198472461632201510 3/pdf_33 $>$. Acesso em: 21 jan. 2021.

BURKE, P. O que é história cultural. Trad. Sergio Gomes de Paula. Rio de Janeiro: Jorge zahar Ed., 2005.

BURKE, P. Hibridismo cultural. São Leopoldo: Ed. Unisinos, 2006.

CARVALHO Júnior, A.D. A construção dos índios pelo Ocidente e seus corpos indomados (Amazônia, séculos XVII e XVIII) In SOUZA, Fábio Feltrin de; WITTMANN, Luisa Tombini (org.). Protagonismo indígena na história. Tubarão: UFFS, 2016, p. 57-86.

CARVALHO, A.W.B. de. Narrativas Guajajara: A voz indígena para além das aldeias.

CESARINO, Pedro de Niemeyer. Histórias indígenas dos tempos antigos. São Paulo: Claro Enigma, 2015.

CHARTIER, R. (1991). O mundo como representação. Estudos Avançados, 5(11), 173 191. Recuperado de https://www.revistas.usp.br/eav/article/view/8601. Acesso em: 05 jun. 2020.

CLAUDINO, Z. K. A formação da pessoa nos pressupostos da tradição, educação indígena Kaingang. Dissertação. (Mestrado em Educação), Programa de Pós-Graduação em educação. Universidade Federal do Rio Grande do Sul. Porto Alegre-RS, 2013.

CUNHA, M. C. Índios no Brasil: história, direito e cidadania. 1. ed. São Paulo: Claro Enigma, 2012. Dissertação. (Mestrado em Letra), Programa de Pós-graduação em Letras e estudos literários da Universidade Federal de Juiz de Fora. Juiz de Fora, 2016.

DORNELLES, S. S; MELO, K. M. R. Sobrevoando histórias: sobre índios e historiadores no Brasil e nos Estados Unidos. Porto Alegre, v. 22, n. 41, p. 173-208, jul. 2015.

ESCALANTE, E. del V. Teorizando las literaturas indígenas contemporáneas. A Contracorriente, Raleigh, NC, 2015.

FAUSTO, Carlos. Inimigos Fiéis: História, Guerra e Xamanismo na Amazônia. São Paulo: Edusp, 2001.

FREIRE, J. R. B.: A canoa do tempo: tradição oral e memória indígena. In: Taqui pra Ti. [Acervo de produção acadêmica]. 2008. Disponível em: http://docplayer.com.br/8372717-Acanoa- -do-tempo-tradicao-oral-e-memoria-indigena-1.html. Acesso em: 02 abr. 2021.

GOMES, G. K.; LIMA, C. D. V. G. Os Fatores da textualidade na produção escrita: um olhar sobre os livros didáticos do ensino médio. II Congresso Nacional de Educação - II Conedu.

Disponível

em: <https://editorarealize.com.br/editora/anais/conedu/2015/TRABALHO_EV045_MD1_SA15_ ID2157_26082015221022.pdf >. Acesso em: out. 2015. 
GOMES, M. P. Os índios e o Brasil - ensaio sobre um holocausto e sobre uma nova possibilidade de convivência. 2. ed. Petrópolis: Vozes, 1991.

GRAÚNA, M. G. F. Contrapontos da Literatura Indígena contemporânea no Brasil. Tese (Doutorado em Letra), Programa de Pós-Graduação em Letras, da Universidade Federal de Pernambuco. Recife: UFPE, 2003.

GRAÚNA, M. G. F. Literatura Indígena no Brasil contemporâneo e outras questões em aberto. Revista Educação e Linguagem, v. 15, n.25, p.266-276, ISSN Impresso: 1415-9902. ISSN Eletrônico: 2176-1043. 2012.

GUTJAHR, Eva. Entre tradições orais e registros da oralidade indígena. SÃO PAULO, 2008. Dissertação. (Mestrado em Antropologia Social) Programa de Pós-Graduação em Antropologia Social. Universidade de São Paulo, São Paulo, 2008.

HALL, S. A identidade cultural na pós-modernidade. Tradução Tomaz Tadeu da Silva, Guaracira Lopes Louro. 11. ed. Rio de Janeiro: DP\&A, 2006.

IBGE. Estudos especiais: O Brasil indígena. Disponível em: https://indigenas.ibge.gov.br/. Acesso em: 10 out. 2020.

JECUPÉ, K. W. A terra dos mil povos: história indígena brasileira contada por um índio. São Paulo: Peirópolis, 1998.

LE GOFF, J. História e memória. Tradução de Bernardo leitão. Campinas: Editora da UNICAMP, 1990.

LOPES DA SILVA, A. Introdução: educação e diversidade. In. GRUPIONI, Luiz Donizete Benzi; SILVA, Aracy Lopes da. A temática indígena na escola: novos subsídios para professores de $\mathbf{1}^{\mathbf{0}}$ e $\mathbf{2}^{\mathbf{o}}$ graus. Brasília: MEC: MARI:UNESCO, 1995.

MASSONI, L.F.H. A história oral e as memórias dos excluídos na escrita do conhecimento. Revista Interdisciplinar Científica Aplicada, Blumenau, v.2, n.4, p. 36-41, TRI IV 2017. ISSN 2525-3824.

MONTEIRO, J. M. O escravo índio, esse desconhecido. In: GRUPIONI, L. D. B. (Org.). Índios no Brasil. Brasília: MEC, 1994.

O desafio da História indígena no Brasil. In. GRUPIONI, Luiz Donizete Benzi; SILVA, Aracy Lopes da. A temática indígena na escola: novos subsídios para professores de $\mathbf{1}^{\mathbf{0}}$ e $\mathbf{2}^{\mathbf{0}}$ graus. Brasília: MEC:MARI:UNESCO, 1995.

Armas e Armadilhas: História e resistência dos índios. In: NOVAES, Adauto (org.). A outra margem do ocidente. São Paulo: Companhia das Letras, p. 237-249,1999.

Tupis, tapuias e historiadores: estudos de História Indígena e do indigenismo. Tese (Livre Docência em História) - Universidade Estadual de Campinas (Unicamp). Campinas, 2001. 
MUNDURUKU, D. Entrevista: Daniel Munduruku. Entrevista concedida a Bruno Ribeiro. Revista Consciência. 5 de fevereiro de 2010. Disponível em: https://revistaconsciencia.com/entrevista-daniel-munduruku/. Acesso em: 16 jun. 2020.

MUNDURUKU, D. Mundurukando. São Paulo: Ed. do Autor, 2010.

Literatura Indígena e o tênue fio entre escrita e oralidade. 2008. Disponível em: www.overmundo.com.br/overblog/literatura-indigena. Acesso em: 11 dez. 2019.

MURA, M. Tecendo Tradições Indígenas. (2016). Tese (Doutorado em História Social) Universidade de São Paulo, São Paulo, 2016.

NEUMANN, E. Práticas letradas guarani: produção e usos da escrita indígena (séculos XVII e XVIII). Tese (Doutorado em História Social) - Universidade Federal do Rio de Janeiro, Rio de Janeiro, 2005.

OLIVEIRA, J. P. O nascimento do Brasil e outros ensaios: "pacificação", regime tutelar e formação de alteridades. Rio de Janeiro: Contra Capa, 2016.

OLIVEIRA, J. P; FREIRE, C.A.R. A Presença Indígena na Formação do Brasil - Brasília: Ministério da Educação, Secretaria de Educação Continuada, Alfabetização e Diversidade; LACED/Museu Nacional, 2006.

OLIVEIRA, R. Identidade étnica, reconhecimento e o mundo moral. Revista anthropológicas, ano 9, v. 16(2), p. 9-40. 2005.

POLLAK, M. Memória e identidade social. Os Estudos históricos, Rio de Janeiro, v. 5, n.10, p. 200-212, Rio de Janeiro, 1992.

POLLAK, M. Memória esquecimento e silêncio. Os Estudos históricos, v. 2, n.3, p. 3-15, Rio de Janeiro, 1989.

POTIGUARA, E. Terra é a mãe do índio. Rio de Janeiro: Grumin, 1989. . Akajutibiró : terra do índio Potiguara. Rio de Janeiro : Grumin, 1994. Metade cara, metade máscara. São Paulo: Global, 2004. Metade cara, metade máscara. 2. ed. Lorena: DM Projetos Especiais, 2018.

SANTOS, F. B. Leitura da literatura indígena na sala de aula: contribuições para o ensino. RIOS Eletrônica - Revista Científica da Faculdade Sete de Setembro. a.11, n. 12 (Jul. 2017) Paulo Afonso, BA: FASETE, 2017.

SANTOS, M. C. dos; FELIPPE, G. G. Protagonismo como substantivo na História. In: SANTOS, Maria Cristina dos; FELIPPE, Guilherme Galhegos (Org.). Protagonismo Ameríndio Ontem e Hoje. Jundiaí: Paco Editorial, 2016. p. 13-52.

SANTOS, S. C. Os direitos dos indígenas no Brasil. In: A. L. SILVA; GRUPIONI, L. D. B. (org.), A temática indígena na escola: novos subsídios para professores de $1^{\circ}$ e $2^{\circ}$ graus. Brasília, DF: MEC/MARI/UNESCO, 1995. p. 87-108. 
SCARAMUZZI, I. A. B. De índios para índios: a escrita indígena da história. Dissertação (Mestrado em Ciência Social), Universidade de São Paulo, Faculdade de Filosofia, Letras e Ciências Humanas, São Paulo, 2008.

SILVA, E. Povos indígenas e ensino de história: subsídios para a abordagem da temática indígena em sala de aula. História \& Ensino, Londrina, v. 8, p. 45-62, out. 2002.

SILVA, G. J. ; COSTA, A. M. Histórias e culturas indígenas na educação básica. Belo Horizonte: Autêntica Editora, 2018.

SOUZA, F. F. de; WITTMANN, L. T. (Org.). Protagonismo indígena na história. Tubarão: UFFS, 2016.

THIÉL, J. Pele silenciosa, pele sonora a literatura indígena em destaque. Belo Horizonte: Autêntica Editora, 2012.

WITTMAN, L. T. (Org.). Ensino (d)e história indígena. Belo Horizonte: Autêntica Editora, 2015.

ZANCHETTA, M.I. Povos indígenas no Brasil: 2006/2010. Socioambiental. São Paulo, Instituto Socioambiental, ano 17, n.49, 2011.

Submetido em 09 de outubro de 2020.

Aceito em 02 de fevereiro de 2021.

Publicado em 09 de abril de 2021. 